\title{
The epidemic of "Black fungus" (mucormycosis) in Covid19 patients in India - a perfect synergy between immuno-suppressive drugs and supportive oxygen that promotes the bio-syntheses of ergosterol (a key component of fungal cell membranes)?
}

\section{Letter}

The "black fungus" (mucormycosis) epidemic in India in April-May 2021 [1] has exacerbated the Covid19 problem, and has been ascribed to over-usage of immuno-suppressive drugs (steroids) and uncontrolled diabetes [2]. This however does not answer the whole question, since these steroids are regularly prescribed for many diseases like RA, and even in the previous year (2020) in India for Covid19 patients.

\section{So what changed?}

Another (troubling) feature of the 2021 Covid19 wave in India has been the requirement (and often unfortunately lack) of supportive oxygen. However, hypoxia (lack of oxygen) is a double-edged sword during pathogenesis [3], as hypoxia at infection sites creates a stressful environment for many host and pathogens. It has been realized that 'manipulation of oxygen levels and/or oxygen-mediated signaling pathways in vivo may have both positive and negative effects on the outcome of' fungal infections [4]. For example, Mucor irregularis has ways to circumvent the hypoxic environment, and thrives in skin where oxygen is minimal [5].

\section{The treatment Amphotericin provides the link - Ergosterol}

'Amphotericin primarily kills yeast by simply binding ergosterol' [6]. Ergosterol is an essential component of cell membranes of fungi and protozoa, analogous to cholesterol in animal cells [7]. Ergosterol biosynthesis requires oxygen [8]. And in low oxygen, cells that cannot make ergosterol absorb it from the external culture environment [9]. When oxygen is in abundance, cells use ergosterol which they biosynthesize [9].

\section{Why not other fungi?}

Oxygen level of the environment modulates the several genes of Mucor [10], while transcriptional profiling showed that the lipid metabolism was more active under hypoxia [11]. Maybe other fungi are not that adapt in reverting back to an aerobic environment, like Mucor. The evolution of sterols as an adaptive response to the rise of terrestrial oxygen has been proposed [12]. Is is possible the Mucor has best retained this primitive response to oxygen stress?

\section{References}

1. Dyer O (2021). Covid-19: India sees record deaths as "black fungus" spreads fear.

2. Bhatt K, Agolli A, Patel MH, Garimella R, Devi M, et al. High mortality co-infections of COVID-19 patients: mucormycosis and other fungal infections .

3. Chung H, Lee YH (2020) Hypoxia: A double-edged sword during fungal pathogenesis? Frontiers in Microbiology 11.

4. Grahl N, Shepardson KM, Chung D, Cramer RA (2012) Hypoxia and fungal pathogenesis: to air or not to air? Eukaryotic cell 11: 560-570. 
5. Castrejón-Pérez AD, Welsh EC, Miranda I, Ocampo-Candiani J, Welsh O (2017) Cutaneous mucormycosis. Anais brasileiros de dermatologia 92: 304-311.

6. Gray KC, Palacios DS, Dailey I, Endo MM, Uno BE, et al. (2012) Amphotericin primarily kills yeast by simply binding ergosterol. Proceedings of the National Academy of Sciences 109: 2234-2239.

7. Rodrigues ML (2018) The multifunctional fungal ergosterol. MBio 9.

8. Parks LW, Adams BG (1978) Metabolism of sterols in yeast. CRC critical reviews in microbiology 6: 301-341.

9. Dhingra S, Cramer RA (2017) Regulation of sterol biosynthesis in the human fungal pathogen Aspergillus fumigatus: opportunities for therapeutic development. Frontiers in microbiology 8: 92.

10. Nagy G, Farkas A, Csernetics Á, Bencsik O, Szekeres A, et al. (2014) Transcription of the three HMG-CoA reductase genes of Mucor circinelloides. BMC microbiology 14: 1-10.

11. Xu W, Peng J, Li D, Tsui CK, Long Z, et al. (2018) Transcriptional profile of the human skin pathogenic fungus Mucor irregularis in response to low oxygen. Medical mycology 56: 631-644.

12. Galea AM, Brown AJ (2009) Special relationship between sterols and oxygen: were sterols an adaptation to aerobic life? Free Radical Biology and Medicine 47: 880-889. 